\title{
Miscellany
}

\section{Winter Business Meeting}

Please note that the Winter Business Meeting will take place at the College following the meeting of Council on the afternoon of Wednesday 3 February 1999 (and not on Tuesday 2 February, as stated in the recent issue of the College News).

\section{Lifetime Achievement Award}

Dr Brian Barraclough with former First Lady, Rosalynn Carter, at the Plaza Hotel, New York, 1998 at the presentation of a lifetime achievement award by the American Foundation for Suicide Prevention.

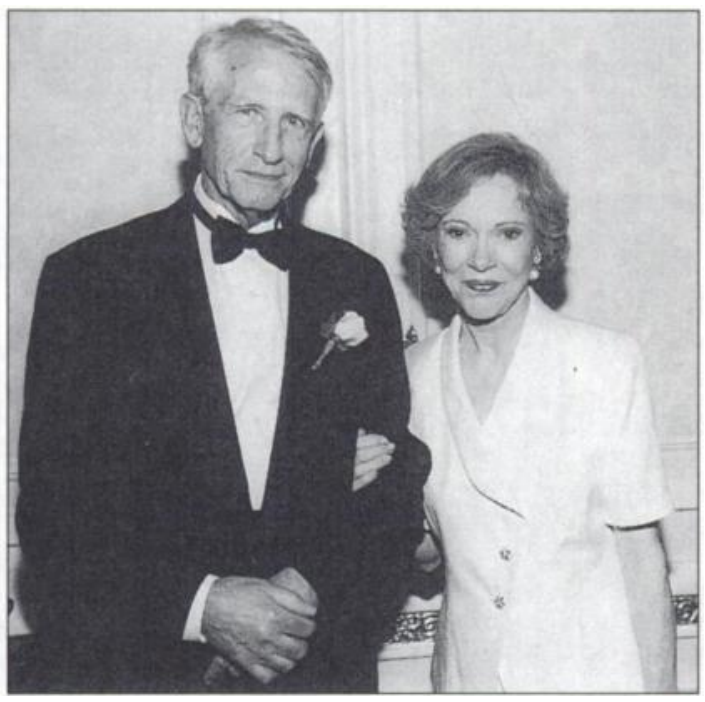

\section{Register of Doctors with an Interest in Transcultural Psychiatry}

The College, in collaboration with the Department of Health, has recently developed a Register of doctors with an interest in transcultural psychiatry. Discussions relating to disseminating this as widely as possible are continuing. Meanwhile, a photocopied version of the Register can be made available upon request to the Department of Postgraduate Educational Services, Royal College of Psychiatrists, 17 Belgrave Square, London SW1X 8PG.

\section{Practice Development Network for In-patient Mental Health Care}

The Centre for Mental Health Service Development (CMHSD), in collaboration with the Division of Nursing Studies, King's College, is setting up a new Practice Development Network for acute in-patient mental health care. The purpose of this initiative is to help re-focus the management and clinical agenda toward the quality of mental health in-patient care. CMHSD is interested in being contacted by practitioners, or managers who feel they are able to demonstrate effective practice in in-patient settings as a resource for the Network. In the longer term, CMHSD is considering drawing up a resource handbook on in-patient good practice that will focus upon examples of effective inpatient care. For further information about the Network contact Penny West, Project Manager, Mental Health Acute In-Patient Practice Development Network, CMHSD on 0171928 4994.

\section{New publications}

A new initiative to help people who have been bereaved come to terms with their loss has been launched by the Royal College of Psychiatrists. Coping with Bereavement is a two-cassette audio-programme presented by the broadcaster and psychiatrist. Professor Anthony Clare. The programme is designed to give bereaved people support, comfort and practical help. It also helps them understand feelings of loss and grief and realise that bereavement can have some positive outcomes. The tapes are available for $£ 13.99$ including postage and packaging, from Talking Life, PO Box 1, Wirral LA7 7D (Telephone: 0151 632 0662).

Promoting Mobility for People with Dementia: A Problem-Solving Approach by Rosemary Oddy has recently been published by Age Concern. The book highlights techniques to achieve and retain mobility and identifies poor communication as a central impediment to improving mobility. Useful suggestions to aid understanding and help the process are provided. This book will be helpful to those working with people suffering from dementia and may be obtained for $£ 14.99$ from The Mail Order Department, 